\title{
Doing the Organizational Tango: Symbiotic Relationship between Formal and Informal Organizational Structures for an Agile Organization
}

\author{
Irena Ali \\ Joint Operations and Analysis Division \\ Defence Science and Technology Group, and \\ Visiting Research Fellow, School of Business, \\ University of New South Wales, Canberra Campus, Canberra, Australia

\section{irena.ali@dsto.defence.gov.au}

\begin{abstract}
This paper reports on research with a broad objective to examine the relationship between two organizational entities, the formally structured organization and informal organizational structures, in a changing operational environment, more specifically during military deployments. The paper draws on organizational and complexity paradigms; based on empirical evidence obtained through qualitative techniques, it describes mechanisms that enable a symbiotic relationship between these two organizational structures in a complex operational landscape. Substantive findings provide insights into the dynamics of the interactions between these structures and illuminate the relationship between three enabling factors - accountability, responsible autonomy, and command and control arrangements - that need to be considered to fully exploit the strengths inherent in both formal and informal structures. Based on these findings, a model for enhancement of organizational agility in response to changes in a complex operational environment is described. The model is predicated on feedback and mutual adjustment of the organization, institution and individual through sensemaking; it illustrates the dynamic nature of interactions that are required for such a response.
\end{abstract}

Keywords: organizational studies, formal and informal organizational structures - symbiotic relationship, organizational adaptation, organizational agility, organizations and institutions, complexity, frameworks, case studies.

Material published as part of this publication, either on-line or in print, is copyrighted by the Informing Science Institute. Permission to make digital or paper copy of part or all of these works for personal or classroom use is granted without fee provided that the copies are not made or distributed for profit or commercial advantage AND that copies 1) bear this notice in full and 2) give the full citation on the first page. It is permissible to abstract these works so long as credit is given. To copy in all other cases or to republish or to post on a server or to redistribute to lists requires specific permission and payment of a fee. Contact Publisher@InformingScience.org to request redistribution permission.

\section{Introduction}

The ongoing relevance of any major organization both within itself and to a nation's social, political, and economic prosperity depends, in large part, on its ability to respond to a rapidly changing operational context. Organizations must be capable of exploiting new opportunities and of coping with new challenges. 
In short, organizations must be adaptive and agile in responding to changes in their operational environment.

Informal collaborative arrangements in organizations and the salient role of informal networks in many aspects of life are well recognized (Ehin, 2004; Liccardi et al., 2007). However, research on organizational responses to the complexity of the environments in which they operate largely focuses on the formal aspects of organizations in terms of their design, structures, and business strategy (Donaldson, 2001; Mintzberg, 1980; Monge \& Contractor, 2003; Monge \& Eisenberg, 1987: Watson \& Weaver 2003). Although, in organizational life, formal and informal structures are intertwined (Rank, 2008; Zenger \& Lazzarini, 2002), what research and discussion there is of informal structures tends to treat these as separate entities. There seems to be a lack of empirical studies looking at the issues that would make the entwinement of formal and informal organizational structures effective and the mechanisms that enable this interaction have not been sufficiently explored.

The current paper builds on earlier published work in the informing sciences discipline where details of the methodological approach of the study are discussed (Ali, 2014). This paper describes a model for enhancement of organizational agility in response to complex operational environment. The model is derived from empirical studies and draws on the strengths of formal and the flexibility of informal organizational structures. The aim of this paper is to add to the body of knowledge for practitioners and researchers in the field of informing sciences and organizational studies in view of constantly evolving nature of informing sciences (Cohen, 2009).

\section{Setting a Scene}

\section{Informal Structures - Their Role and Significance}

The literature on informal networks seems to suggest that the extent and the types of networks individuals form affects many aspects of individuals' lives, from their health, identity, and wellbeing to career advancement and power in organizations (Brass, Galaskiewicz, Greve \& Tsai, 2004; Granovetter, 1983; Kilduff \& Tsai 2003; Krackhardt, 1990; Krackhardt \& Hanson, 1993). In the field of knowledge management, knowledge distribution, and gaining competitive advantage, the role of informal networks is well supported (Awazu, 2004; Cross, Parker, Prusak, \& Borgatti, 2001; Hoffman, Hoelscher, \& Sherif, 2005; Kurland \& Pelled, 2000; Plickert, Cote, \& Wellman, 2007).

Although these aspects of the significance of informal networks are important, the role of informal networks in the management of emergency and crisis situations is of particular interest because change and uncertainty are constant features of any operational environment. Response to a modern disaster, whether natural or man-made, presents many challenges. Traditionally, disaster response management was based, to a large extent, on a command and control standpoint. However, based on analysis of disaster response over the past years, an alternative perspective on management of complex situations has emerged. This view emphasizes the importance of informal networks and hastily formed networks (Denning, 2006), and trust between individuals and agencies in crisis management (Denning, 2006; O'Brien \& Ali, 2006; O'Neil \& O'Brien, 2004) as disaster management seldom works according to standard operating procedures or neatly defined roles and responsibilities. Management of emergency situations requires flexibility, adaptability, and fast information flows. After analyzing the response to the terrorist attack of September $11^{\text {th }} 2001$, the December $26^{\text {th }} 2004$ tsunami, the August $29^{\text {th }} 2005$ Katrina hurricane, and the October $8^{\text {th }} 2005$ earthquake in Pakistan, Denning $(2006$, p15) stated that the quality of the response is dependent not on response planning or on new equipment, but on the quality of the networks that come together to provide relief. 
O'Neil and O'Brien (2004) researched command and control arrangements in relation to informal communication networks that operate in parallel with the formal organizational networks during emergency situations. Their study results indicate that the timeliness for communicating critical information was very marginal when using formal channels. On the other hand the informal information was both timely and accurate, and it was observed that experienced crews made full use of such information to make decisions as to the safety of their teams. Therefore, when considering organizational structures, O'Neil and O'Brien (2004) note that a trusted community of interests is a prerequisite for accepting informal information flows for decision making.

Other examples of the accuracy of information disseminated through informal networks and the overall utility and speed with which informal networks operate are those of the shooting at Virginia Polytechnic Institute and State University in Blacksburg on $16^{\text {th }}$ April 2007, fires in Southern California, and the $12^{\text {th }}$ May 2008 earthquake in China's Sichuan province (Winerman, 2009). During the 2011 earthquake in Christchurch, New Zealand was in need of a Mass Casualty Incident (MCI) tracking board and an informal network of web based emergency operation centre (WebEOC) administrators. New Zealand obtained these within an hour of a request being made through an informal network of WebEOC users. Those networks were formed for information and assistance sharing, at the local and international level (Thornley, 2013).

O'Brien and Ali (2006) examined the significance of informal networks in a range of disasters that involve inter- and intra-organizational information flows between civil and military organizations. They point out that a communication strategy must optimize the process of transferring critical data to enable local decisions to be made based upon local data, which may change from minute to minute. In such cases the only information available may come from informal channels some of which may be non-expert. Therefore, the command and control processes need to be enhanced with a degree of empowerment and autonomy embedded into the system to better recognize the role of informal networks (O'Brien \& Ali, 2006).

On the other hand, an account of the recent fires in Kinglake (Victoria, Australia) illustrates the dire outcome when adhering to the formal policy that the blaze remains the responsibility of the district in which it ignites until it is formally passed over to whatever region it enters. The result of holding on to this directive was that the office responsible for the Kinglake Ranges refused to take action until the correct procedure had been followed and the responsibility for the fire was formally handed over. By the time this happened, it was too late to save Kinglake (Hyland, 2011).

These examples suggest that in many emergency situations, informal networks of individuals affected by disasters are an effective force for response and recovery with minimal time, training, and financial investment. Also, what is worth noting from these instances is that when people are under threat, perceived or actual, they go into what appears to be an intensified information seeking activity. This behavior is consistent with "uncertainty reduction theory" (Afifi \& Weiner, 2002; Berger \& Calabrese, 1975) and the research indicates that in conditions of high uncertainty and task complexity people seek more information from different sources for decision-making than for routine tasks and that they show preference for verbal as opposed to written media (de Alwis, Majid, \& Chaudhry, 2006). It also appears, that emergency managers have a desire to control the flow of information and, as a result, informal network users often end up bypassing the authorities (Winerman; 2009). Granger (1999) points out that commitments and competence in disaster management are of little value if there is no effective communication and willingness to share knowledge and information between formal organizations and informal groups or communities. This intensified information seeking behavior in rapidly changing environments and the need for sharing information through formal and informal means are of particular relevance to this study because the subjects of this research are confronted by and have to manage uncertainty, changing operational context, and crisis situations. 


\section{Structuring Organizations for Operational Contingencies}

For an organization to successfully respond to changes in operational landscape, its structure needs to be aligned both internally (in terms of who performs the work, how it is performed, and what business processes are in place) and externally (in terms of the environment (contingency) in which the work takes place). Thus, structure becomes the key linking element in terms of internal and external fit (Clegg, Kornberger, \& Pitsis, 2005; Donaldson 2001; Hollenbeck et al., 2002).

Over the decades studies have been conducted into organizational design where changing environmental contingencies are key. As the result, a concept of mechanistic and organic organizational structures arose (Burns \& Stalker, 1961). In the 1970s, a prominent theory of structuring of organizations was propagated by Mintzberg (1979) which posits that for every situation and task an organization is facing, there is a specific structure that fits best and that an organization's structure emerges from the interplay of a variety of organizational attributes, e.g., strategy, environment, and task nature. In the early 2000s the concept of an 'edge organization' arose where power for decision making is to be dynamically distributed away from the center to those involved in execution, referred to as 'power to the edge' (Alberts \& Hayes, 2003b). A prominent contemporary theory for structuring organizations (which corresponds, to a large degree, to Mintzberg's theory) is known as the structural contingency theory (SCT) (Burns \& Stalker, 1961; Donaldson, 2001). SCT provides a major framework for the study of organizational design and argues that effective organizations are those that are structured to be fit-for-purpose for the contingencies they encounter.

There is a clear relationship between organizational agility and the 'fit-for-purpose' concept of contingency theory. This relationship between organizational design and the environment is also evident in a number of other contemporary approaches, for example Stafford Beer's Viable System Model (Beer, 1972, 1985), Dave Snowden's Cynefin framework (Kurtz \& Snowden, 2003), and the Alberts-Hayes Command and Control (C2) model defined by allocation of decision rights, by patterns of interaction amongst the actors and by distribution of information (Alberts \& Hayes, 2006).

The organizational studies referred above advocate that, in order to increase organizational agility and respond more quickly to operational changes, it requires broadening of span of control, flattening of hierarches, and wide range of interactions. A flat structure better enables interaction, which facilitates development of the 'wisdom of collectives' through synergistically combining attributes of members to produce outcomes beyond the capacity of an individual (Salas, Rosen, Burke, \& Goodwin, 2009; Surowiecki, 2004); this increases organizational capacity for performance. Organizational agility requires harnessing the power inherent to informal organizational structures and organizational and institutional inputs.

\section{Organizations and Institutions}

Although in some literature and particularly in popular speech the term 'organization' is used to cover both the organizational and institutional aspects and these terms are often used interchangeably, scholars point out the difference between the two (Helmke \& Levitsky, 2004; Khalil, 1995; North, 1991). Institutions are referred to as bodies providing 'rules of the game' in terms of constraints and incentives that are instrumental in doing business, whereas organizations are about how the 'players of the game' are structured through defined roles and positions in a relationship to each other in order to achieve specific objectives (Department for International Development, 2003; Helmke \& Levitsky, 2004).

Further, Khalil (1995) highlights the distinction between organizations and institutions by stating that while goals (ends) define the organization, means by which the ends are achieved constitute 
the institution. The means include paradigms and conventions, formal and informal, and the agents acting according to ends in the light of means. Collectively, these paradigms and traditions provide expectations about behavior as well as shaping incentives that motivate and influence its members, their behaviors and performance, and thus determine the success or otherwise of missions or projects (Department for International Development 2003).

North (1991) characterizes institutions as follows:

- they are socially determined and govern social, political, economic, and cultural exchanges and interactions

- they define a range of choices and regulate risk tolerance

- they evolve incrementally, linking the past with the present and the future

- they provide incentives and set the tone for development.

Organizations exist to secure the interests of their members within the existing institutional framework, while seeking to influence that framework. Therefore, there is an intimate and dynamic relationship between the organizations and institutions. The interaction between them determines the nature of exchanges taking place and the overall outcomes (Khalil, 1995; North, 1991).

The distinction between organizations and institutions is of particular relevance here as it is the institution that sets a framework for organizational conduct involving formal and informal structures and is a vehicle that drives a change.

\section{Study Setting and Research Approach}

The research is situated in a military domain with specific focus on deployments. Operational environment, in particular, requires agility of response in terms of adaptation to suit a new situation, the flexibility of organizational processes, and the diversity of potential solutions to problems. Whilst there is a considerable body of evidence and research about informal collaborative arrangements in organisations and achieving results through informal networks (Cross \& Parker, 2004; Kilduff \& Tsai, 2003; Krackhardt \& Hanson, 1993), the research in those areas in the military during deployments appears to be scarce. Moreover, the research reported in literature seems to mainly rely on social network analysis (SNA), and, while the SNA offers explanations to 'what' type of questions, it does not always provide deep insights into 'why' and 'how' such phenomena arise. Although there seems to be sufficient anecdotal evidence (Burnett, Henman, \& Sims; 2008; Cause, Ritcher, \& Wilmott, 2005, Chin, Reynolds, Wheeler, O’Donnel, \& Pascoe, 2007) and some empirical evidence (Talbot \& O'Toole, 2008) about the significance of informal networks in the military in operational environments, relatively little is known about the dynamics of the co-existence of formal organisation and informal networks, what gives rise to these structures during deployment, and whether these networks contribute to mission outcomes and affect command chains. Therefore, there is a need for theoretical and empirical underpinnings of the role of informal networks in operations in order to effectively harness their power and provide guidance for their exploitation during operations. This research aimed to identify factors that support coexistence of informal networks within a formally structured organization in order to enable agile response through a spectrum of environmental contingencies.

These queries are exploratory, seeking to gain insights into complex organizational phenomena, and the research is based on qualitative methodology consisting of two phases. Phase 1 comprised 146 semi-structured interviews with military personnel deployed in three different deployments between 2001-2007 (combat, humanitarian, and disaster relief operations), and Phase 2 comprised a workshop with 26 participants deployed during 2007-2009. The Phase 2 study aimed, first, to determine consistency of the findings and to corroborate results of Phase 1 in terms of the accura- 
cy of interpretation in the data analysis and, second, to extend the research by discussing priorities and actions that could be taken to harness the strengths associated with formally structured command and control organizations and informal networks in future operations.

All interview data was thematically coded by means of template analysis (King, 2004; Waring \& Wainwright, 2008) and a subset of data pertaining to formal and informal organizational structures was further analysed in depth using template and Cynefin (Kurtz \& Snowden, 2003; Snowden \& Boone, 2007) frameworks. The Cynefin framework was used to represent interactions between the formal organisation and informal networks and for describing different circumstances of the operational environment and the activity of informal networks in that environment.

The outcome of Phase 1 analysis provided a foundation upon which to design and obtain further data in the Phase 2 study. The workshop methodology (Phase 2 study) drew on the theory of sensemaking; sensemaking is retrospective and individuals and groups draw meaning of past events and experiences (Weick, 1995, 2007; Weick, Sutcliffe, \& Obstfeld, 2005). Since the focus of this paper is a model for enhancement of organizational agility in complex operating environment, the methodological description here is brief and the overall research design is illustrated in Figure 1. Details of the methodological approach are discussed in Ali $(2011,2014)$.

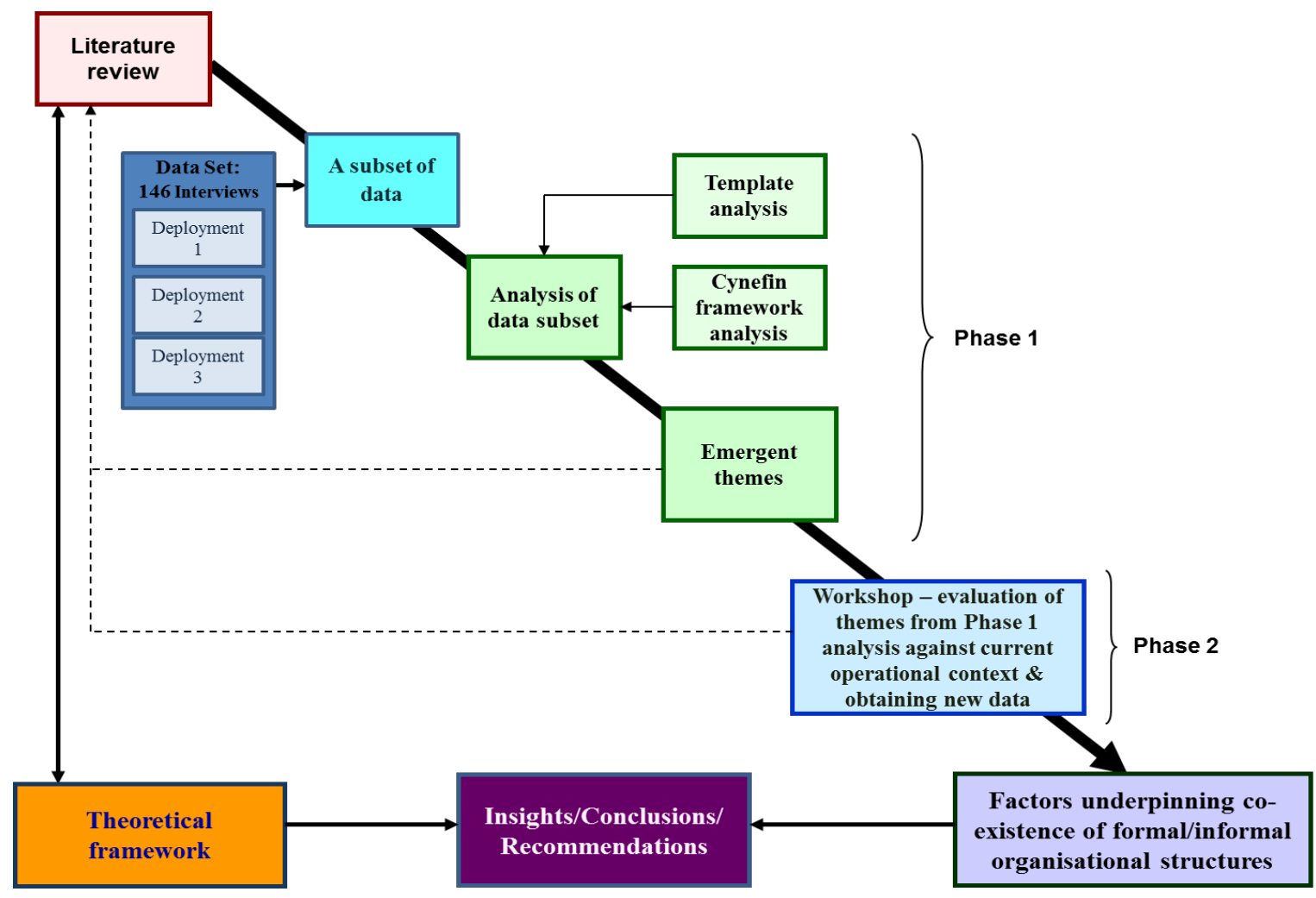

Figure 1. Overview of the research design

Military organization is particularly suited for such study as it is a visibly hierarchical organization where formal and informal organizational structures exist. The military faces changes in operational context more than any other organization. The spectrum of operations ranges across combat, peace keeping, disaster relief, and humanitarian assistance deployments, potentially involving coalition and civil-military arrangements within whole-of-government operations. 


\section{Study Outcome}

The findings from the analysis of interviews (Phase 1) are multilayered and shed light on contingencies that led to informal network activity and modus operandi of these networks during the three deployments under study. Data analysis demonstrated that informal networks were instrumental in attaining mission goals; these networks were mobilized by a variety of causes and were heavily relied on for desired outcomes. The individuals involved in informal networks were bound by shared values and belief in the purpose of their mission. However, in order to supplement the formal organizational system with the informal organizational structures when the operational imperative necessitated it, three themes emerged to be of greatest concern amongst the participants. These are accountability, responsible autonomy, and an appropriate command structure.

In the military, answerability for decisions and performance to civilian and the military authorities is a central tenet, and public scrutiny of the military is ever increasing. Traditionally, military culture places considerable emphasis on authority and accountability with the hierarchical model of accountability being usually applied (Australian Department of Defence, 2009). More recently, call for a personal accountability model has been put forth (Black, 2011). On the other hand, Australian military culture is also known as being a 'can do' culture, demonstrated in this study by self-organizing behavior and innovative approaches to problems, regardless of the hurdles, in order to accomplish the mission. This is where the accountability dilemma is becoming apparent and the problem of 'many hands' (Thompson, 1980) comes into play; what accountability model should be applied when an informal way of doing things is dictated by an operational imperative and involves collectives of individuals (Kohn, Kalloniatis, \& Ali, 2012)? This issue requires careful consideration in any organization.

The type of command and control (C2) approach is a driving factor in the ability of an organization to respond in a timely manner to changes in its operational context and is a major determinant in achieving agility. Alberts and Hayes (2003a) explain that it is C2's ability to translate information into actionable knowledge that will provide the best opportunity to achieve agility through a 'power to the edge' approach as it allows "... individuals to interact in unplanned ways to create understandings and options not previously possible" (p. 90). From the perspective of organizational theory, to be fit-for-purpose in complex environments does not imply either a homogenous or heterogeneous organizational structure (Donaldson, 2001; Kurtz \& Snowden, 2003; Mintzberg, 1979). For instance, while centralized C2 and decision making is appropriate in some circumstances, distributed decision making is needed in others and, as the operational situation changes, so should the distribution of decision rights. Similarly, while in one part of an organization a machine bureaucracy may be the most efficient structure, in another part of the same organization this type of structure would be quite inappropriate. Thus the issue of appropriate $\mathrm{C} 2$ structure in view of emergent behavior driven by complexities in operational environment requires consideration.

The term 'responsibility' is about ownership of a situation and forward thinking in terms of what can be done about a given predicament. Responsibility is shared rather than ascribed to an individual (Uhr, 1999). Autonomy involves the extent to which the job permits or demands selfdirection and individual discretion (Jaffee, 2001). The concept of responsible autonomy (Fairtlough, 2005) extends Alberts and Hayes' (2006) concept of 'allocation of decision rights' where the formal allocation of decision rights may not correspond to their actual distribution during deployments. Therefore, responsible autonomy is where the scope of responsibility is more encompassing. It involves consideration of a longer and wider trajectory of events rather than mere discharge of assigned duties, where sequences of decisions are called for without recourse to a superior but with the exercise of discretion. Responsible autonomy is an important aspect in determining how much one can relax $\mathrm{C} 2$ structures and organizational policies. The role of 
command is to seek novel solutions to mission problems (Pigeau \& McCann, 2002) and, in order to do so, competency (intellectual, emotional, and interpersonal), authority (legal and personal), and responsibility (extrinsic and intrinsic) need to be addressed.

These themes, once addressed, were seen as enabling relationship between formal and informal organizational structures. While it is necessary to address them individually (Ali, 2011), the interrelationship amongst these enablers must also be considered in order to leverage the intrinsic strength of formal and informal organizational structures.

These three themes were explored in the workshop (Phase 2 study), and analysis of the workshop data, whilst confirming many of the earlier findings, provided further insights into ways of addressing these enablers. The findings of Phase 2 study support the notion that the relationship of the three enablers should be supported by doctrinal guidance, clear and explicit commander intent, and education and training at all levels (see Figure 2). These together were found to promote a mutually supportive and mutually beneficial relationship of the formal and informal organizational structures.

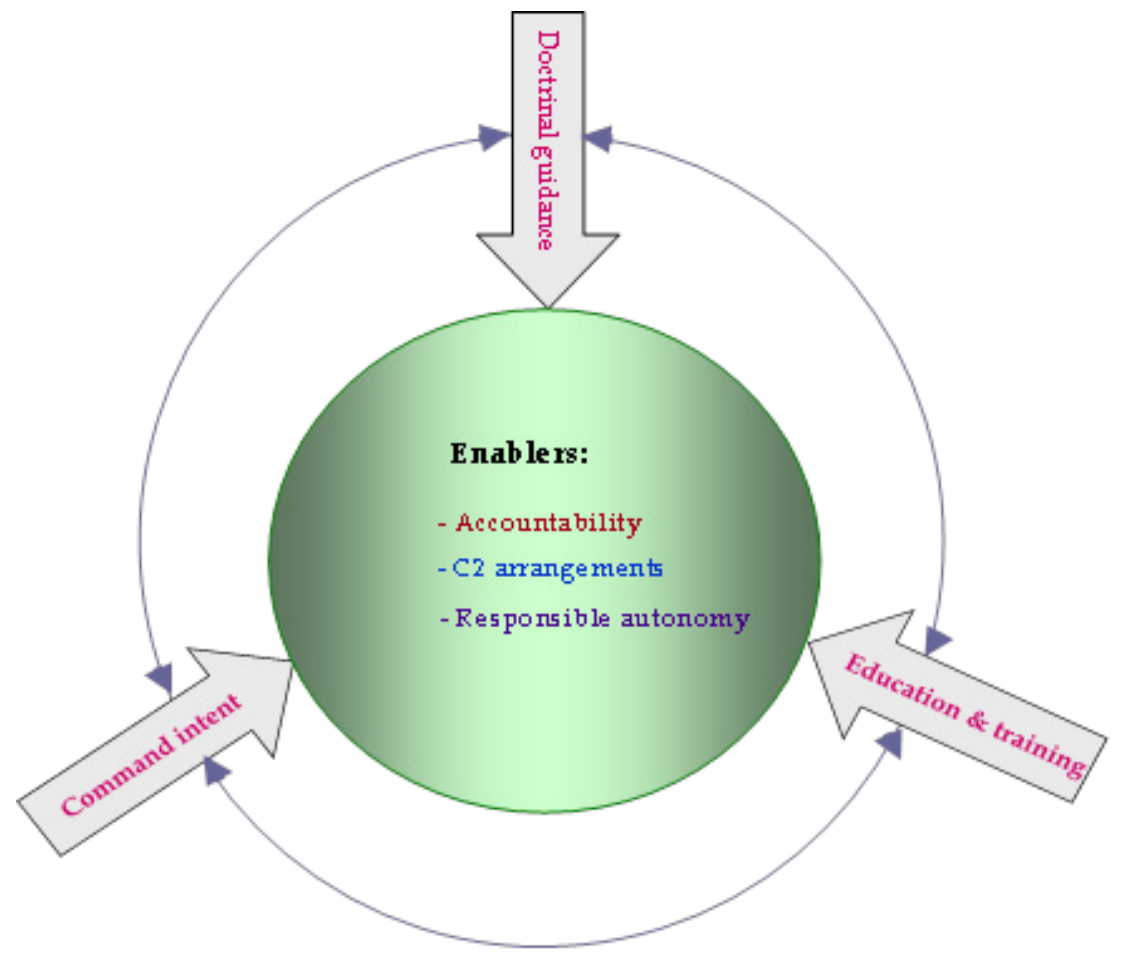

Figure 2. Interrelationship of the enablers and their supporting factors

The literal meaning of 'doctrine' is what is taught within a group as its corporate beliefs, principles, or faith (Gordon, 1996, p. 580). However, doctrine is more than just a set of corporate beliefs; it is a living entity based on what has been learnt. It is based on principles and is much richer than just a procedural document. Its aim is to link theory, history, and empirical evidence to foster initiative and creative thinking. It is a basis for education and training. It underpins all organizational activity and contributes to turning ideas into results. Therefore, it needs to be explicit and unambiguous and the value adding role of informal networks needs to be subsequently reflected in doctrine.

The workshop participants identified command intent with emphasis on clarity of intent to be of paramount importance in complex operations where formal and informal structures need to draw on each other. Pigeau and McCann (2000) identify two components of intent: explicit and implic- 
it. While explicit intent comprises orders, questions, and answers and is publicly communicated in the form of written or verbal directives, implicit intent is a combination of habits, experiences, beliefs, and values that reflect personal, military, cultural, and national expectations. However, regardless whether it is implicit or explicit, the intent needs to be shared and understood by all involved, albeit via different modes of conveyance.

While $\mathrm{C} 2$ arrangements and responsible autonomy were identified as the key requirements for the effective relationship of informal networks and formally structured command during deployments, the workshop participants emphasized that appropriate skills are needed to exercise responsible autonomy as well as "greater education and understanding of when and how to use such [informal] networks and how they can best complement formal networks". They stressed the need for specially devised education and training programs if responsible autonomy is to be exercised in the theatre of operations: a systematic program aimed at developing empowerment skills, so that individuals can gain the necessary confidence to assume responsibility, and an appropriate framework of accountability to exercise responsible autonomy.

Appropriately designed education and training programs will sufficiently prepare future warriors to assume responsibility that comes with more autonomy, rather than feeling overpowered by the amount of autonomy, as reported by some of the interviewees: "What authority do we have to make stuff that we've never been trained in." While the notion of education and training usually implies programs for the junior ranks, the study results show that adaptation of command style is necessary as the operational context changes, and this adaptation can be achieved by tailoring education programs for higher command. The study participants made a point that it is education, not just training, that is needed to address the interaction between informal networks and formal organizational structures as each represent a different facet of learning. Therefore, such programs, apart from the specifics of military art, need to address interpersonal communication techniques so as to maintain clarity of intent, and all aspects of informal networking, including its advantages and limitations, together with issues surrounding accountability.

\section{Achieving Symbiosis - Interplay of Institution, Organization, and the Individual}

The synthesis of the findings from the interview program and the workshop shows that in an uncertain environment both the strengths and guidance offered by the formal organizational system and the flexibility and agility of informal networks need to be taken advantage of. In fact, in order to effectively respond to novel situations these two need to have a symbiotic relationship, rather than to just coexist. A symbiotic relationship is mutually beneficial and is a partnership between entities of different kinds, whereas when entities just coexist they may compete in some aspects. The term symbiosis, first used in the 1870 s with reference to biological systems, is now widely used when two different species or entities enjoy a mutually beneficial relationship (Budowski, 1976). Likewise, formal and informal organizational structures are very different entities but they need to exist in a mutually beneficial relationship to enhance organizational agility.

A holistic and fruitful symbiosis between these formal and informal structures requires that the enablers and their supporting factors are situated in the context of and enacted by organizational, institutional, and individual inputs. While formal organizational structures comprising organizational and institutional inputs are important and assist more with a control based approach, informal inputs assist more with an approach based on trust relationships and a sharable intent, which includes self-organizing behavior and formation of informal networks.

As pointed out earlier, organizations and institutions display different properties and serve different purposes; therefore, it is essential to delineate these nuances in a proposed model that encompasses a relationship of formal and informal structures. A diagrammatic representation of the ho- 
listic symbiotic relationship between the enablers and their supporting factors in a context of organizational, institutional, and individual agent's intrinsic properties and inputs is depicted in Figure 3.

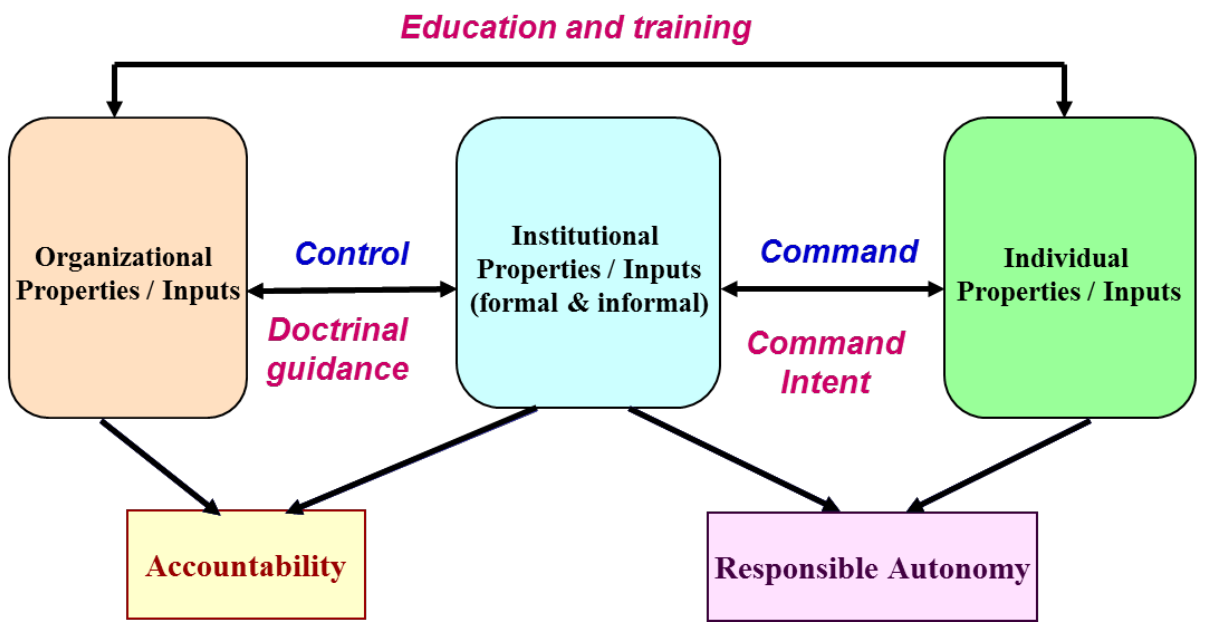

Figure 3. Formal and informal organizational structures the model for organizational symbiosis

In this model the properties and/or inputs represent characteristics of an organizational, institutional, and individual nature that can either facilitate or impede achievement of the set goals or outcomes in a given operational context.

Organizations are collectives of players who come together for a purpose to pursue organizational goals ('ends') and they rely on organizational inputs to achieve that purpose. Organizational properties and inputs encompass goals, structures, operating procedures, and rules that are readily observable through written documents. Organizational inputs also include resources, training and education programs, facilities, equipment/capabilities, budget, and a multitude of processes specific to an organization that advance organizational objectives (Department for International Development, 2003; Khalil, 1995).

Institutional inputs and properties, on the other hand, represent the means needed to pursue organizational ends (Khalil, 1995). As discussed earlier, institutions govern individual and collective behavior through formal means, such as paradigms, norms, policies, and doctrine, as well as the degree of autonomy, discretion, and empowerment. They also govern behavior through informal means, such as customs and traditions together with shared understanding that define the actual behavior of agents. These are, in most part, socially derived and therefore not accessible through written documentation (North, 1991). While formal institutional means are important, the findings clearly showed that study participants relied on informal 'institutions' to a large extent and these shaped their behavior.

While the relationship between institution and organization is an important one, it cannot be considered on its own and void of inputs provided by the individual agents who are a part of this system. The effectiveness of this relationship is determined by individuals who operate within that system (Werner \& DeSimone, 2009). Individuals with their intrinsic capabilities comprising knowledge, experience, effort, will and motivation, propensity for creativity, innovation, and interaction exert influence on and are influenced by the institutional and organizational properties and by the dynamic of that relationship.

The diagram in Figure 3 provides an explicit representation of the study findings in terms of enablers and their supporting factors and organizational, institutional, and individual properties and 
inputs, in achieving a symbiotic relationship between the formal and informal structures in complex environments. As discussed earlier, control, in military terms, is defined by and involves structures, facilities, procedures, policies, resources, and capabilities for planning and directing a mission (Pigeau \& McCann, 2002). Therefore, control necessitates interaction between and drawing on the organizational and institutional inputs.

Accountability is the capacity of organizational agents to answer for actions undertaken, may they be successful or unsuccessful, in relation to organizational goals (Bovens, 1998; Kohn et al., 2012). Implementation of accountability requires organizational and institutional inputs. It is linked to the concept of control and is made explicit by doctrine. Command, on the other hand, relies on creativity, innovation, motivation, and adaptability grounded in knowledge and experience. This is a human-centred domain and involves individual inputs. While creative expression is an attribute of an individual input, the authority of command relies on institutional inputs. Pigeau and McCann (2002) concur with the importance of individual attributes for command but they stress that it does not end there. Effective command requires support of institutional inputs, both formal and informal. For command to be effective it requires appropriate education and training programs, hence organizational input in this area is important.

Autonomy is considered a human need and a capability intrinsically important to human development and functioning (Ryan \& Deci, 2006). However, autonomy is not freedom to do whatever one wants to do. Autonomy is pursued in social context and is constructed through interaction between institution and an individual agent. To exercise autonomy requires supportive conditions and the internal sense of being autonomous (Fairtlough, 2005; Ryan \& Deci 2006). For agents to act autonomously they need to be supported by appropriate education and training programs to equip them with the necessary skills and knowledge to act with confidence according to command intent.

\section{Achieving Agility through a Symbiotic Relationship between Formal and Informal Organizational Structures}

I have shown that the interplay between the enablers, their supporting factors, and institutional, organizational, and individual properties contributes to the maintaining of a symbiotic relationship between formal and informal organizational structures; however, the wider issue is how this symbiotic relationship can be instrumental in attaining agility of response to various contingencies in the operational environment. The model in Figure 4 illustrates the dynamic nature of interactions that are required for an agile response. It is predicated on feedback and mutual adjustment of the organization, institution, and individual through sensemaking.

In this model, the operational environment denotes the front line environment where organizational business takes place. This environment is determined by external conditions, for example, wider government policies and regulatory frameworks, political climate, multiplicity of players involved, type of deployment, and degree of operational complexity. Although the operational context is mostly outside the realms of organizational, institutional, and individual control, the operational context shapes the way individuals, organizations, and institutions behave, derive meaning, make sense of experiences, and, as a result, arrive at decisions. 


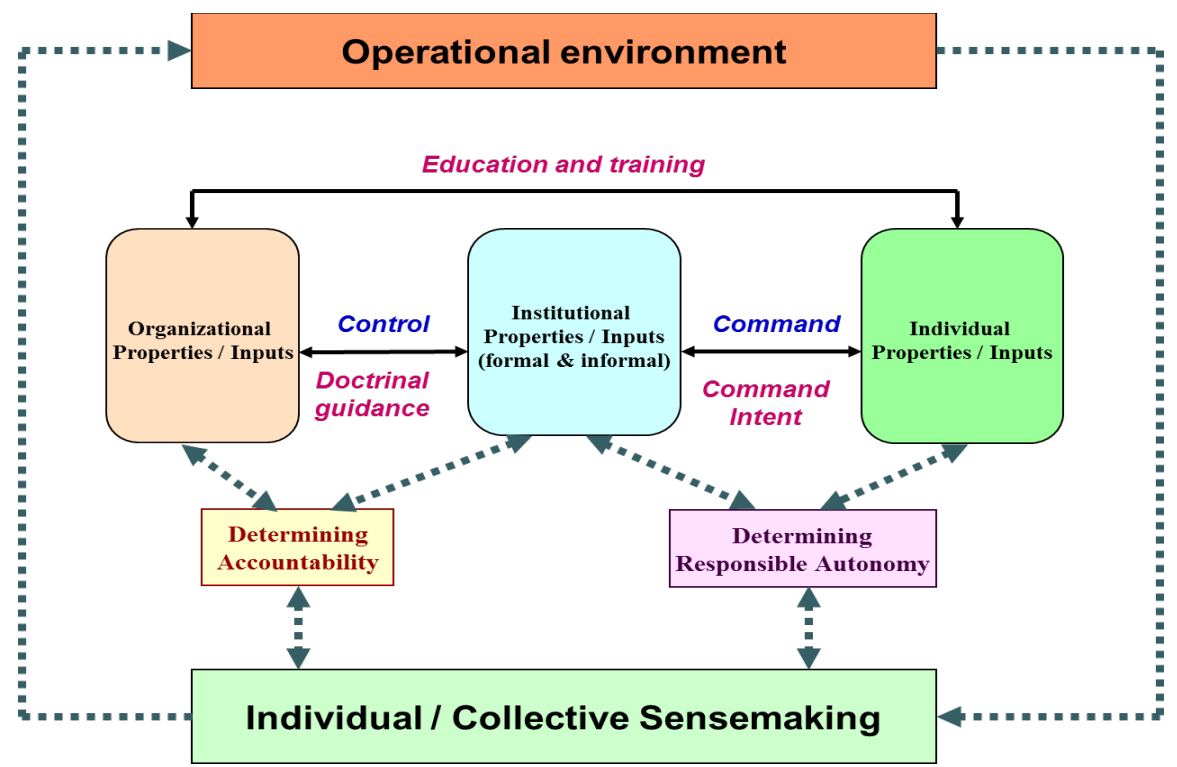

Figure 4: A process view for enhancement of agile response in complex environments

Sensemaking is an ongoing human process that is social, involves retrospective analysis, and is driven by plausibility rather than accuracy. It involves understanding and creating a 'frame of reference' to direct interpretation (Weick, 1995; Wilson \& Wilson, 2012). The focus of sensemaking is to provide the decision maker with a plausible understanding of a complex environment. The process of sensemaking involves interactions and feedback to the organization and sometimes serendipitous and not fully understood interactions and relationships. Through sensemaking, agents investigate and/or question the organizational processes and rules, for instance, how is accountability dealt with? what degree of authority/autonomy do I have? In this model, the feedback and interactions between each component of the model are essential for mutual adjustment in responding with agility to changes in the operational environment.

Since organizations are defined by their ends and institutions regulate the actions of the agents (Khalil, 1995), it means mutual adjustment needs to take place between the individual (agents in the theatre) and institutional inputs. However, formal institutional inputs such as policies and doctrine are slow to change, with doctrine being based on learnt experiences. Therefore, informal institutional inputs are crucial if this mutual adjustment is to take place, and it is at this point where a symbiotic relationship between the formal and informal institution pays dividends. Also, since it is the organization that spells out the 'ends' that the agents in the theatre strive to achieve, the agility of adjustments made as a consequence of feedback from agents on deployment will, therefore, be reliant on fit-for-purpose organizational structures.

The model in Figure 4 can also serve as a diagnostic tool to determine, first, whether organizational structures, processes, and procedures are sufficiently agile for a given operational context; second, whether different approaches need to be considered for achieving outcomes; and third, by means of feedback from individual and/or collective agent(s), whether appropriate accountability frameworks and levels of autonomy are in place to take action in pursuit of organizational ends. For this model to be used as a diagnostic tool it requires robust feedback to the organization from either an individual agent or a collective of agents in the theatre of operations. The importance of feedback to the organization to guide amendments to inefficient formal processes was highlighted as a priority issue by workshop participants.

A combination of institutional, organizational and individual inputs provides a necessary framework for individual or collective sense and decision making. Institutional and organizational in- 
puts offer a bounded context to exercise responsible autonomy within an appropriate framework of accountability. Individuals form an understanding of their operational environment or a situation based upon these frameworks but also draw on their own experiences, knowledge, training, education, and cognitive capabilities. This study has illustrated that individuals interpret events within and outside of their organizations to justify and enable action.

Pigeau and McCann (2002) posit that these institutional inputs must be responsive and, if required, must be adapted or changed to suit the evolving operational situation. In such cases, formal and informal structures will not merely exist alongside each other but will rather work together and play a key role in applying formal policies for effective outcomes. This means that accountability frameworks and degree of responsible autonomy are not static but are determined in response to changes in operational context. Exercising responsible autonomy requires trust in an agent's ability to initiate appropriate actions in response to the dynamics in the environment. Responsible autonomy also means that these actions are taken at their discretion and involve an element of risk taking. Determining an appropriate level of responsible autonomy is also a process requiring clear boundaries set by the institutional inputs in a given operational context (Atkinson \& Moffat, 2005; Fairtlough, 2005; Penrose, 2000).

\section{Beyond Military Organizations}

Although this research was conducted within a military organization, the results have application to any organization operating in a complex, uncertain, and changing environment. The tasks of a leader and a manager in any organization are analogous to that of a military commander. The difference may be that for organizational units and their leaders no 'enemy' exists, but the environment is nevertheless changing and capable of surprising. While the concepts of command and control have a military connotation, at the most generic level they can be viewed as a form of leadership and management infrastructure for planning and organization. These concepts involve the exercise of authority in the form of leadership and direction over assigned resources. Therefore, in non-military organizations, 'command' can be viewed as a definition of overall system objectives or goals through leadership, whereas 'control' is parallel to the management and monitoring of processes and activities that lead to the attainment of these objectives and goals (Builder, Bankes, \& Nordin, 1999). Since 'command' requires creativity, innovation, motivation, and adaptability grounded in knowledge and experience (Pigeau \& McCann, 2002), which is a human domain, it is akin to 'leadership' in organizational theory and practice. Leadership requires creativity, consideration of human needs, and creation of an organizational climate and culture that motivates, inspires self-initiative, and stimulates improvements and innovation (Jaffee, 2001).

Therefore, the three enablers of the symbiotic relationship between formal and informal organizational structures - accountability, leadership and management (command and control) approaches, and responsible autonomy - are equally applicable for non-military organizations operating in complex environments.

\section{Concluding Remarks}

Organizational effectiveness depends on matching organizational structures and processes to environmental contingencies. Different operational contexts will typically generate different types of problems - stable environments will generate routine problems and complex environments will more likely generate a stream of unique problems (Verdon \& Wang, 2009), requiring innovative and agile responses. Complex operational environments require different methods of strategic planning, organizational architectures, and leadership and managerial approaches than those suited to a stable context. 
Gill (2013) advocates that to cope with complexity we need to understand it. This study demonstrates empirically that for organizations operating in a complex landscape, a complementary relationship between the formal and informal organizational structures is necessary for agility. Formal organizations have a defined structure, informal networks, on the other hand, do not have one neither do they have a 'best' way of operating. They emerge and adapt to the demands of the environment. This study's findings highlight that, to a large degree, the agility of response that impacts on effectiveness of outcomes is also dependent on interactions that are based on trust, reciprocity, and transparency - the principles that underpin functioning of informal organizational structures.

Effectiveness of such interactions can be either enhanced or inhibited by organizational culture as an aspect that influences the behavior of communication and information sharing between individuals and groups within the organization. The overall organizational culture is shaped and influenced by institutional norms and the individuals within an organization. However, individuals regulate their position within organizational culture and situate themselves around emerging issues.

Whether it is in a military setting or in organizations in general, where formal and informal organizational structures work well, it is not simply because of their purposes and design or form. It is more generally because they are invested with legitimacy, sustained by institutional support, and backed by associated organizational capacity to ensure effective implementation (Leftwich \& Sen, 2010). The interdependence between organizations and institutions based on interaction and feedback provides legitimacy and support for a symbiotic relationship between formal and informal organizational structures.

This research illustrates the intricate web of human interactions juxtaposed with organizational realities in the context of a rapidly changing operational environment. It shows that the formal and informal organizational structures cannot be dealt with separately, but, as in a dance, they must be considered as being intertwined in a symbiotic relationship in order to secure the desired agility.

\section{References}

Afifi, W. A., \& Weiner, L. (2002). Information seeking across contexts. Human Communication Research, 28(2), 207-212.

Alberts, D., \& Hayes, R. E. (2003a). Command and control in the information age. Washington, DC: CCRP Publication Series.

Alberts, D., \& Hayes, R. E. (2003b). Power to the edge: Command and control in the information age. Washington, DC: CCRP Publication Series.

Alberts, D., \& Hayes, R. E. (2006). Understanding command and control. Washington, DC: Department of Defense, CCRP.

Ali, I. (2011). Coexistence or operational necessity: The role of formally structured organisation and informal networks during deployments. 16th International Command Control Research and Technology Symposium (ICCRTS). Quebec City, Canada, June 2011. Retrieved from http://www.dtic.mil/dtic/tr/fulltext/u2/a547172.pdf

Ali, I. (2014). Methodological approaches for researching complex organizational phenomena. Informing Science: the International Journal of an Emerging Transdiscipline, 17, 59-73. Retrieved from http://www.inform.nu/Articles/Vol17/ISJv17p059-073Ali0476.pdf

Atkinson, S. R., \& Moffat, J. (2005). The agile organization: From informal networks to complex effects and agility. Washington, DC: US Department of Defense Command and Control Research Program. 
Australian Department of Defence. (2009). Executive Series Australian Defence Doctrine Publication 00.1: Command and control. Canberra: Defence Publishing Service.

Awazu, Y. (2004). Knowledge management in distributed environments: Role of informal network players. 37th Hawaii International Conference on System Sciences, Hawaii, IEEE.

Beer, S. (1972). Brain of the firm. London: The Penguin Press.

Beer, S. (1985). Diagnosing the system for organizations: Handbook of organizational structure, design and fault diagnosis. London: John Wiley.

Berger, C. R., \& Calabrese, R. J. (1975). Some exploration in initial interaction and beyond: Toward a developmental theory of communication. Human Communication Research, 1, 99-112.

Black, R. (2011). Review of the Defence accountability framework. Canberra: Australian Government, Department of Defence: 126.

Bovens, M. (1998). The quest for responsibility: Accountability and citizenship in complex organizations. Cambridge, UK: Cambridge University Press.

Brass, D. J., Galaskiewicz, J., Greve, H. R., \& Tsai, W. (2004). Taking stock of networks and organizations: A multilevel perspective. Academy of Management Journal, 47(6), 795-817.

Budowski, G. (1976). Tourism and environmental conservation: Conflict, coexistence, or symbiosis? Environmental Conservation, 3(1), 27-31.

Builder, C. H., Bankes, S. C., \& Nordin, R. (1999). Command concepts: A theory derived from the practice of command and control. Santa Monica, CA: RAND, National Defense Research Institute.

Burnett, M., Henman, B., \& Sims, A. (2008). An analysis of command and control arrangements in two recent operations. Australian Defence Force Journal, 176, 75-92.

Burns, T. \& Stalker, G. M. (1961). The management of innovation. London: Tavistock Publications.

Cause, R., Ritcher, W., \& Wilmott, M. (2005). Solomon Islands case study focusing on effects based operations. Canberra: Defence Science and Technology Organisation: 44.

Chin, M., Reynolds, H., Wheeler, S., O'Donnel, S., \& Pascoe, C. (2007). A study of the future coalition command, control and communications (C3). Canberra: Defence Science and Technology Organisation: 85 .

Clegg, S., Kornberger, M., \& Pitsis, T. (2005). Managing and organizations: An introduction to theory and practice. London: Sage Publications.

Cohen, E. B. (2009). A philosophy of informing science. Informing Science: the International Journal of an Emerging Transdiscipline, 12, 1-15. Retrieved from http://www.inform.nu/Articles/Vol12/ISJv12p001-015Cohen399.pdf

Cross, R., \& Parker, A. (2004). The hidden power of social networks: Understanding how work really gets done in organizations. Boston: Harvard Business School Press.

Cross, R., Parker, A., Prusak, L., \& Borgatti, S. P. (2001). Knowing what we know: Supporting knowledge creation and sharing in social networks. Organisational Dynamics, 30(2), 100-120.

de Alwis, G., Majid, S., \& Chaudhry, A. S. (2006). Transformation in managers' information seeking behaviour: A review of the literature. Journal of Information Science, 32(4), 362-377.

Denning, P. (2006). Hastily formed networks: Collaboration in the absence of authority. Reflections: the SoL Journal, 7(1), 1-8.

Department for International Development. (2003). Promoting institutional and organisational development: DFID.

Donaldson, L. (2001). The contingency theory of organizations. Thousand Oaks, CA: Sage. 
Ehin, C. (2004). Hidden assets: Harnessing the power of informal networks. New York: Springer Science $\&$ Business Media Inc.

Fairtlough, G. (2005). Three ways of getting things done: Hierarchy, heterarchy and responsible autonomy in organizations. Dorset, UK: Triarchy Press.

Gill, T. G. (2013). Complexity, cybernetics, and informing science: Building a better mousetrap. Systemics, Cybernetics and Informatics, 11(9), 53-68.

Gordon, A. (1996). The rules of the game: Jutland and British Naval Command. Great Britain: John Murray.

Granger, K. (1999). An information infrastructure for disaster management in Pacific Island countries. Canberra: Australian Geological Survey Organisation.

Granovetter, M. (1983). The strength of week ties: A network theory revisited. Sociological Theory, 1, 201233.

Helmke, G., \& Levitsky, S. (2004). Informal Institutions and comparative politics: A research agenda. Perspectives on Politics, 2(4): 725-740.

Hoffman, J. J., Hoelscher, M. L., \& Sherif, K. (2005). Social capital, knowledge management, and sustained superior prerformance. Journal of Knowledge Management, 9(3), 93-100.

Hollenbeck, J. R., Moon, H., Ellis, A. P., West, B. J., Ilgen, D. R., Sheppard, L., ... \& Wagner III, J. A. (2002). Structural contingency theory and individual differences: Examination of external and internal person-team fit. Journal of Applied Psychology 87(3): 599-606.

Hyland, A. (2011). Kinglake - 350. Melbourne: Text Publishing.

Jaffee, D. (2001). Organization theory: Tension and change. Boston: McGraw-Hill.

Khalil, E. (1995). Organizations versus institutions. Journal of Institutional and Theoretical Economics $15(1 / 3), 445-466$.

Kilduff, M. \& Tsai, W. (2003). Social networks and organizations. London: Sage Publications.

King, N. (2004). Using templates in the thematic analysis of text. In C. Cassell \& G. Symon (Eds.), Essential guide to qualitative methods in organizational research. London: Sage.

Kohn, E., Kalloniatis, A., \& Ali, I. (2012). The accountability dilemma in the Network Centric Era. Fairfax, VA, USA.

Krackhardt, D. (1990). Assessing the political landscape: Structure, cognition, and power in organizations. 17th International Command and Control Research and Technology Symposium, 19-21 June 2012. Administrative Science Quarterly, 35(2), 342-369.

Krackhardt, D., \& Hanson, J. R. (1993). Informal networks: The company. Harvard Business Review, JulyAugust, 104-111.

Kurland, N. B., \& Pelled, L. H. (2000). Passing the word: Toward a model of gossip and power in the workplace. Academy of Management Review, 25(1), 429-458.

Kurtz, C. F., \& Snowden, D. J. (2003). The new dynamics of strategy: Sense-making in a complexcomplicated world. IBM Systems Journal, 47(3), 462-483.

Leftwich, A., \& Sen, K. (2010). Beyond institutions: Institutions and organizations in the politics and economics of poverty reduction - A thematic synthesis of research evidence. Manchester: IDPM, School of Environment and Development, University of Manchester.

Liccardi, I., Ounnas, A., Pau, R., Massey, E., Kinnunen, P., Lewthwaite, S., \& Sarkar, C. (2007). The role of social networks in students' learning experiences. The 12th Annual Conference on Innovation and Technology in Computer Science Education. Dundee, Scotland.

Mintzberg, H. (1979). The structuring of organizations. New York, Prentice-Hall Inc. 
Mintzberg, H. (1980). Structure in 5's: A synthesis of the research on organization design. Management Science, 26(3), 322-341.

Monge, P. R., \& Contractor, N. S. (2003). Theories of communication networks. Oxford: Oxford University Press.

Monge, P. R., \& Eisenberg, E. M. (1987). Emergent communication networks. In L. L. Jablin, K. H. Roberts, and L. W. Porter (Eds.), Handbook of organizational communication (pp. 304-342). London: Sage.

North, D. C. (1991). Institutions. Journal of Economic Perspectives, 5(1), 97-112.

O'Brien, F., \& Ali, I. (2006). Formal and informal networks during emergency situations: The impact for information strategy. 11th ICCRTS - Coalition Command and Control in the Networked Era. Cambridge, UK, September 2006.

O'Neil, J., \& O'Brien, F. (2004). The role of informal communications in C2 decision making. 9th ICCRTS - Coalition Transformation: An evolution of people, processes, and technology to enhance interoperability. Copenhagen, September 2004.

Penrose, J. (2000). Human problems in organizational devolution. In C. McCann \& R. Pigeau (Eds.), The human in command: Exploring the modern military experience (pp. 147-160). New York: Kluwer Academic.

Pigeau, R., \& McCann, C. (2000). Redefining command and control. In C. McCann \& R. Pigeau (Eds.), The human in command: Exploring the modern military experience (pp. 163-184).

Pigeau, R. \& McCann, C. (2002). Reconceptualizing command and control. Canadian Military Journal, $3(1)$.

Plickert, G., Cote, R. R., \& Wellman, B. (2007). It's not who you know, it's how you know them: Who exchanges what with whom?" Social Networks, 29, 405-429.

Rank, O. N. (2008). Formal structures and informal networks: Structural analysis in organizations. Scandinavian Journal of Management, 24, 145-161.

Ryan, R. M., \& Deci, E. L. (2006). Self-regulation and the problem of human autonomy: Does psychology need choice, self-determination, and will?_Journal of Personality, 74(6), 1557-1585.

Salas, E., Rosen, M. A., Burke, C. S., \& Goodwin, G. F. (2009). The wisdom of collectives in organizations: An update of the teamwork competencies. In E. Salas, G. F. Gooodwin, \& C. S. Burke (Eds.), Team effectiveness in complex organizations: Cross-disciplinary perspectives and approaches (pp. 3979). New York: Psychology Press, Taylor and Francis Group.

Snowden, D. J., \& Boone, M. E. (2007). A leader's framework for decision making. (cover story). Harvard Business Review, 85, 68-76. Harvard Business School Publication Corp.

Surowiecki, J. (2004). The wisdom of crowds: Why the many are smarter than the few. London: Abacus.

Talbot, S., \& O'Toole, P. (2008). Resourceful interactions: Social capital, networking and learning in the Australian army. 5th International Conference on Intellectual Capital and Knowledge Management \& Organizational Learning, New York.

Thompson, D. (1980). Moral responsibility of public officials: The problem of many hands. American Political Science Review, 74(Dec), 905-915.

Thornley, L. (2013). Virtuous circle helps Christchurch communities recover from earthquakes. Retrieved March 2013 from http://www.hrc.govt.nz/news-and-media/media/virtuous-circle-helps-christchurchcommunities-recover-earthquakes

Uhr, J. (1999). Three accountability anxieties. Australian Journal of Public Administration, 58(1), 98-101.

Verdon, J., \& Wang. Z. (2009). The last mile of the market: How networks, participation and responsible autonomy support Mission Command and transform personnel management. Ottawa: Department of National Defence, Canada. 
Waring, T., \& Wainwright, D. (2008). Issues and challenges in the use of template analysis: Two comparative case studies from the field. The Electronic Journal of Business Research Methods, 6(1), 85 - 94.

Watson, S., \& Weaver, G. R. (2003). How internationalization affects corporate ethics: Formal structures and informal management behavior. Journal of International Management, 9(1), 75-93.

Weick, K. E. (1995). Sensemaking in organizations. Thousand Oaks, CA: Sage Publications.

Weick, K. E. (2007). The generative properties of richness. Academy of Management Journal, 50(1), 1419.

Weick, K. E., Sutcliffe, K. M., \& Obstfeld, D. (2005). Organizing and the process of sensemaking. Organization Science, 16(4), 409-421.

Werner, J. M., \& DeSimone, R. L. (2009). Human resource development. Mason, OH: South-Western Cengage Learning.

Wilson, M. J., \& Wilson, M. L. (2012). A comparison of techniques for measuring sensemaking and learning within participant-generated summaries. Journal of the American Society for Information Science and Technology, 64(2),291-306.

Winerman, L. (2009). Social networking: Crisis communication. Nature, 457(7228), 376-378.

Zenger, T. R., \& Lazzarini, S. G. (2002). Informal and formal organization in new institutional economics. The New Institutionalism in Strategic Management, 19, 277-305.

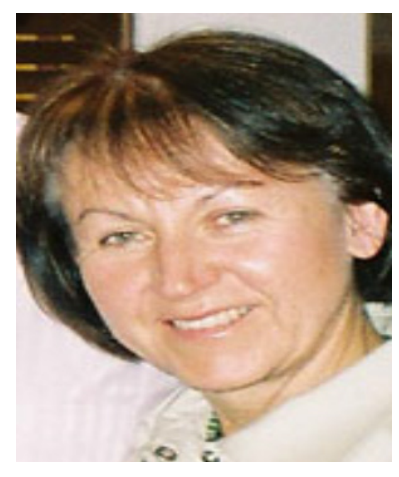

\section{Biography}

Irena Ali is a Defence Scientist and she joined Defence Science and Technology Organisation (DSTO) in Australia in 1999. DSTO is now known as DST Group. Irena's educational background spans fields of biomedical science (BApplSc), Information Studies (Grad Dip Lib \& Grad Dip Arts (Info St), MA by research (Info St), and Information Systems $(\mathrm{PhD})$ with special interest in socio-organizational issues in complex environments. In 2009 she was a recipient of the Secretary of Defence Fellowship to investigate factors associated with the formal organization and informal networks that affect the ability of the organization to operate and survive in a complex environment. Irena has an extensive research experience and is a member of a team responsible for researching and developing the human and organizational aspects of learning, knowledge mobilization, sensemaking, command and control, and situation awareness. She has published and presented both nationally and internationally in the field of organizational and social learning, human dimension of NCW and future warfare, fatigue and shift design, measuring situation awareness, and coexistence of formal and informal organizational structures in complex environments (over 90 publications). In her free time Irena is pursuing her culinary passion for hot and spicy food and enjoys skiing, bush walking, cycling, and snorkeling. 